\title{
Contribuições da Economia para a Alfabetização Científica Uma Proposta para a Educação Básica
}

\author{
Patricia Franzoni ${ }^{1}$ \\ José Claudio Del Pino \\ Eniz Conceição Oliveira ${ }^{3}$
}

\begin{abstract}
Resumo
A ciência faz parte do cotidiano e saber ciências tornou-se uma condição necessária para que a sociedade possa participar de maneira mais eficiente nos processos de tomadas de decisão. É imprescindível que o ensino de ciências garanta a alfabetização científica para os alunos e apresente 0 conhecimento científico como uma das possibilidades de interpretação do real, sem deixar de levar em consideração outras formas de conhecimento na leitura do mundo. Isso posto, propõe-se uma discussão sobre alfabetização científica e sua importância no ensino de ciências, estabelecendo relações entre economia, tecnologia, sociedade e meio ambiente. 0 professor deve desenvolver uma postura dialógica em suas aulas, promovendo debates, trazendo também situações/problemas presentes no nosso cotidiano. Conclui-se que 0 ensino de ciências não deve se restringir apenas à transmissão de conhecimentos, é preciso que se estabeleçam relações entre teoria e prática para se alcançar a alfabetização científica. É importante destacar que a introdução da economia na Educação Básica, em uma perspectiva de Ciência, Tecnologia e Sociedade (CTS) pode contribuir para a alfabetização científica, por meio do caráter interdisciplinar da ciência, formando pessoas mais bem orientadas a respeito da realidade socioeconômica, o que se reflete nos indicadores de qualidade da educação e no desenvolvimento econômico do país.
\end{abstract}

Palavras-chave: Alfabetização científica. Ensino. Sociedade. Economia.

1 Graduada em Ciências Econômicas (Furg). Mestre em Economia (UFPB/João Pessoa). Professora-adjunta (Economia/Furg). Discente no Programa de Pós-Graduação - Doutorado em Ensino (Univates) e bolsista da Coordenação de Aperfeiçoamento de Pessoal de Nível Superior (Capes). patriciafranzoni@furg.br

2 Doutor em Engenharia de Biomassa (UFRGS). Pós-doutor (Universidade Aveiro-Portugal). Professor do PPG Educação em Ciências (UFRGS) e do PPG Ensino (Univates). delpinojc@yahoo.com.br

3 Graduada, mestre e doutora em Química (UFRGS).Professora titular (Univates).eniz@ univates.br 


\title{
CONTRIBUTIONS OF THE ECONOMY TO SCIENTIFIC LITERACY: A PROPOSAL FOR BASIC EDUCATION
}

\begin{abstract}
Science is a part of our everyday life and knowing science has become a necessary condition for a efficiently social participation in decision-making processes. It is imperative that science education guarantees scientific literacy for students and presents scientific knowledge as one of the possibilities of the real interpretation, while also considerating other forms of knowledge in reading the world. Thus, it is proposed a discussion about scientific literacy and its importance in science education, establishing relations between economy, technology, society and environment. The teacher needs to develop a dialogical attitude in his classes, promoting debates, bringing also daily life situations/problems, so that the student can participate with his own ideas. It is concluded that the science teaching should not only be restricted to the transmission of knowledge, it must establish relations between theory and practice, In a CTS (Science, Technology and Society) perspective and the environment to achieve scientific literacy. It is also important to emphasize that the introduction of the economy in basic education can contribute to scientific literacy through the interdisciplinary nature of science, preparing well informed people about the socio-economic reality, which reflects in the indicators of education quality and the country's economic development.
\end{abstract}

Keywords: Scientific literacy. Teaching. Society. Economy.

Recebido em: 8/6/2017

Aceito em: 31/7/2017 
Segundo Sasseron e Carvalho (2008), o conceito de Alfabetização Científica (AC) surge nos círculos educacionais norte-americanos em meados do século 20 , indicando a necessidade de uma educação voltada para a formação científica e que potencialize o desenvolvimento econômico do país.

A ciência, entretanto, não pode ser compreendida de modo isolado, para tomarmos uma decisão é necessário considerar aspectos antropológicos e culturais do sujeito. E é nesse aspecto que precisamos fazer uma abertura para outras áreas do conhecimento, para que elas auxiliem nas explicações dos fenômenos e na compreensão dos modos como os sujeitos proporcionam sentido aos fenômenos vivenciados.

Pensando nos motivos socioeconômicos, culturais cívicos e práticos das decisões a serem tomadas no dia a dia, Diaz, Alonso e Mas (2003) mencionam a alfabetização científica como uma atividade que se desenvolve gradualmente ao longo da vida e, assim, a veem conectada às características sociais e culturais do indivíduo.

Assim, identificamos a ciência como uma forma de compreender a realidade, utilizando-se de um método para desvelar racionalmente os fenômenos. O conhecimento científico, ao explicar o mundo também nos dá possibilidades de intervenção nele; a ciência produz uma representação do real e não o real em sua essência. Quando utilizamos a ciência como único critério para tomar uma decisão, corre-se o risco de que esta se constitua uma decisão tecnocrática, ou seja, orientada somente para os fins.

A alfabetização científica não pode ser compreendida somente como a ação de ensinar conceitos e ideias para os alunos, mas também em um ensino que apresente o conhecimento científico como uma das possibilidades de interpretação do real.

Gil-Pérez e Vilches-Peña (2001) afirmam ser esperado que por meio da alfabetização científica os cidadãos usem informações que possuem sobre ciências para tomar decisões e realizar opções; que possam se envolver com discussões públicas sobre ciência e tecnologia e que compreendam como se constroem os conhecimentos científicos. 
Dessa forma, o ensino de ciências não deve se restringir à transmissão de conhecimentos, mas deve mostrar aos alunos a natureza da ciência e a prática científica e, sempre que possível, explorar as relações existentes entre ciência/ tecnologia/sociedade. A investigação seria uma das formas de ensinar e favorecer a AC, defendendo um currículo baseado em propostas de situações-problema nas quais os alunos se envolvam na busca por uma resposta.

Os professores, entretanto, continuam desenvolvendo suas disciplinas de forma isolada, sem fazer grandes articulações com temas e assuntos que têm tudo a ver um com o outro. É como se as disciplinas estivessem desconectadas umas das outras e do mundo ao seu redor.

O professor precisa ter um compromisso ético com os alunos, reconhecendo que cabe a ele transformar situações do dia a dia em tópicos de discussão e relacionar o conhecimento científico com o cotidiano. Segundo Freire (1980), o professor deve desenvolver uma postura dialógica em suas aulas, promovendo debates em que o aluno possa tomar parte apresentando com suas próprias ideias.

Nessa perspectiva, a partir de uma pesquisa bibliográfica, o objetivo do presente artigo é discutir a importância da alfabetização científica e sua relação com a economia, com o propósito de contribuir para o ensino de ciências. Este ensino com ênfase em CTS deve tratar das relações entre explicação científica, tecnológica, solução de problemas e tomadas de decisão sobre temas do nosso dia a dia, ou seja, deve existir uma integração entre educação científica e tecnológica com a discussão de questões econômicas, sociais e políticas.

Além da introdução e conclusão deste artigo, a segunda seção do texto refere-se ao conceito, objetivo e de que maneira a alfabetização científica é discutida por diversos autores ao longo dos anos. A terceira seção deste estudo faz referência ao ensino de ciências, à formação do cidadão e à necessidade de reformular os currículos, com a finalidade de torná-los mais atrativos aos estudantes. A quarta seção trata dos movimentos conhecidos como Ciência, Tecnologia e Sociedade (CTS) e Ciência, Tecnologia, Sociedade e Ambiente (CTSA) que destacam a importância de os professores trabalharem com conteúdos que preparem o aluno para ser um cidadão crítico, capaz de compreender 
os problemas da sociedade, da realidade econômica do seu país e saber agir sobre eles. Por fim, a quinta seção apresenta a proposta de levar economia para a Educação Básica, visando a contribuir no processo de alfabetização científica.

Uma sociedade informada é capaz de realizar as melhores escolhas, sejam econômicas, políticas, sociais e/ou ambientais. Diante deste contexto, pode-se questionar: De que forma o acesso ao conhecimento de economia na Educação Básica pode contribuir para AC e tornar as disciplinas mais significativas, estabelecendo uma conexão da escola com o cotidiano?

\section{Alfabetização Científica}

A alfabetização não é somente a capacidade de reter e memorizar um conjunto de códigos, mas sobretudo a capacidade de conciliar uma leitura do mundo e leitura da palavra, que garanta ao sujeito uma organização lógica do pensamento e uma visão crítica de mundo.

[...] A alfabetização é mais que o simples domínio psicológico e mecânico de técnicas de escrever e de ler. É o domínio destas técnicas em termos conscientes [...] Implica numa autoformação de que possa resultar uma postura interferente do homem sobre seu contexto (FREIRE, 1980, p. 111).

Freire (1980) define a alfabetização como um processo que permite o estabelecimento de conexões entre o mundo em que a pessoa vive e a palavra escrita e de tais conexões nascem os significados e as construções de saberes.

De alguma maneira, porém, podemos ir mais longe e dizer que a leitura da palavra não é apenas precedida pela leitura do mundo, mas por uma certa forma de escrevê-lo ou de reescrevê-lo, quer dizer, de transformá-lo através de nossa prática consciente. Este movimento dinâmico é um dos aspectos centrais, para mim, do processo de alfabetização (FREIRE, 2005, p. 20).

Fourez (1994, p. 23) ressalta que o objetivo da alfabetização científica "não é uma série de conhecimentos particulares, mas um conjunto global que nos permite reconhecermo-nos no universo". Fourez reconhece que o ensino 
de ciências tomou a dimensão de aulas de transmissão dogmática de conceitos e teorias, em que pouco ou nenhum espaço foi oferecido para discussões que permitissem entender como a ciência e seus significados são construídos. "A partir desta realidade é necessário renovar o ensino de ciências. Essa renovação pode ser entendida como a combinação de alguns eixos: o econômico, político, o social e o humanista" (FOUREZ, 1994, p. 16).

A alfabetização científica significa possibilidades de que a maioria da população disponha de conhecimentos científicos e tecnológicos necessários para se desenvolver na vida diária, ajudar a resolver problemas e as necessidades de saúde e sobrevivência básica, tomar consciência das complexas relações entre ciências e sociedade (FURIÓ et al., 2001).

Laugksch (2000) constata, por meio de suas pesquisas, que para uma pessoa ser considerada alfabetizada cientificamente deve ter conhecimento das relações entre ciência e sociedade, saber sobre a ética que monitora o cientista, conhecer a natureza da ciência, diferenciar ciência de tecnologia, possuir conhecimento sobre conceitos básicos das ciências e por fim perceber e entender as relações entre as ciências e as humanidades (PELLA; O'HEARN; CALVIN, 1966, p. 199).

Segundo Milaré e Alves Filho (2010), um indivíduo alfabetizado científica e tecnologicamente é capaz de argumentar, negociar e dialogar com outros indivíduos, de enfrentar situações diversas e concretas de maneira racional, além de saber conduzir a relação entre saber-fazer e poder-fazer.

Chassot (2000) afirma que a globalização determinou a inversão no fluxo de conhecimento [...], a velocidade e quantidade de informação fazem parecer os professores cada vez menores. A tecnologia sem dúvida auxilia no processo de alfabetização científica, em que o professor perdeu o centro de referência do saber. Antes o conhecimento vinha praticamente da escola, agora é o mundo exterior que invade as escolas.

Levy (1999) complementa que o conhecimento passou a ser compartilhado com o mundo virtual, em que é possível trocar ideias e saberes, desenvolver a inteligência coletiva e transformar a informação em conhecimento. 
Sasseron e Carvalho (2011) criam três eixos estruturantes da Alfabetização Científica (AC) com o objetivo de fornecer bases suficientes e necessárias de serem consideradas no momento da elaboração e planejamento de aulas visando à Alfabetização Científica.

O primeiro desses três eixos estruturantes, segundo os autores, refere-se à compreensão básica de termos, conhecimentos e conceitos científicos fundamentais com finalidade de possibilitar ao aluno um maior entendimento das informações e situações do cotidiano. O segundo eixo preocupa-se com a compreensão da natureza das ciências e dos fatores éticos e políticos que circundam sua prática. $\mathrm{O}$ terceiro e último eixo da $\mathrm{AC}$ compreende o entendimento das relações existentes entre ciência, tecnologia, sociedade e meio ambiente, tendo em mente o desejo de um futuro sustentável para a sociedade e o planeta.

De acordo com Sasseron e Carvalho (2011) as propostas didáticas que surgirem respeitando esses três eixos devem ser capazes de promover o início da $\mathrm{AC}$, pois terão criado oportunidades para trabalhar problemas envolvendo a sociedade e o ambiente.

Segundo Capra (1996), o mundo não é estável, pronto e acabado, em que os fatos se repetem com regularidade e de forma previsível, o que abre espaço para uma nova percepção de realidade, em ver o mundo como processo em constante transformação.

Entender a ciência nos facilita contribuir para controlar e prever as transformações que ocorrem na natureza. Assim teremos condições de fazer com que essas transformações sejam propostas, para que conduzam a uma melhor qualidade de vida. Isto é, a intenção é colaborar para que essas transformações que envolvem o nosso cotidiano sejam conduzidas para que tenhamos melhores condições de vida. Isso é muito significativo [...] (CHASSOT, 2003, p. 91).

Chalmers (1994) discute os limites da ciência e o significado das suas dimensões sociais e políticas, fazendo uma crítica à pseudociência, ao método experimental e à objetividade científica, ao considerar a ciência não como um corpus rígido e fechado, mas como uma atividade aberta que está em permanente construção. 
Dessa forma, a história é importante para compreender de que maneira o conceito de alfabetização científica é discutido ao longo dos anos. O conhecimento não deve ser baseado unicamente em teorias, conceitos e leis sem estabelecer relações com as mudanças histórico-sociais, o contexto e de que forma a ciência é produzida. A ciência deveria fazer referência à realidade $\mathrm{e}$ ser produzida em um contexto interdisciplinar. ${ }^{4}$ Segundo Japiassu (1976), a interdisciplinaridade surge para superar a fragmentação entre os conteúdos, para suprir a necessidade de articular teoria e prática e devido à distância dos conhecimentos uns dos outros e da realidade.

Os estudantes deveriam interagir com o mundo, analisar, refletir, questionar, levantar hipóteses, trocar ideias e perceber que a ciência é resultante de uma construção. A ciência não é lugar de certezas absolutas, nossos conhecimentos científicos são necessariamente parciais e relativos. Segundo Chassot (2003), a Alfabetização Científica deve ser considerada um conjunto de conhecimentos que facilitam as pessoas a fazerem uma leitura do mundo em que vivem.

Para Chassot (1994), a ciência é uma linguagem, ser alfabetizado cientificamente significa ler a linguagem em que está escrita a natureza. Um analfabeto científico é incapaz de uma leitura do universo. De acordo com o autor, é desejável que os alfabetizados cientificamente não apenas façam uma leitura do mundo em que vivem, mas também entendam a necessidade de transformá-lo em algo melhor.

Segundo Fourez (1994), é inaceitável ensinar ciências de maneira exclusivamente teórica, mostrando-as sem vínculo com a possibilidade de realizações na vida cotidiana. Nesse sentido, percebe-se que a relação entre a alfabetização científica e a realidade vivida é a finalidade mais importante do ensino de ciências.

\footnotetext{
4 "A interdisciplinaridade caracteriza-se pela intensidade das trocas entre os especialistas e pelo grau de integração real das disciplinas no interior de um mesmo projeto de pesquisa" (JAPIASSU, 1976, p. 74).
} 


\section{O Ensino de Ciências e a Cidadania}

Hurd (1998) menciona em seu artigo que Spencer (1859) já considerava a necessidade de as escolas ensinarem o que faz parte da vida cotidiana dos alunos [...], uma vez que a sociedade depende dos conhecimentos que a ciência constrói, é preciso que esta mesma sociedade saiba mais sobre a ciência em si e seus empreendimentos. "É preciso incluir no ensino de ciências questões ambientais, políticas, econômicas, éticas, sociais e culturais relativas à ciência e tecnologia" (SANTOS, 2007, p. 485).

Bybee e Deboer (1994), Fourez (1994), Bybee (1995), Hurd (1998), Jiménez-Aleixandre et al. (2000), Yore et al. (2003) e Lemke (2006), expressam a necessidade da escola permitir aos alunos compreenderem e saberem sobre Ciências, suas tecnologias e as relações das duas com a sociedade como condição para preparar cidadãos para o mundo atual. Assim sendo, emerge a necessidade de um ensino de Ciências capaz de fornecer aos alunos não somente noções e conceitos científicos, mas também é importante e preciso que os alunos possam "fazer ciência", sendo defrontados com problemas autênticos nos quais a investigação seja condição para resolvê-lo. É preciso também proporcionar oportunidades para que os alunos tenham um entendimento público da ciência, ou seja, que sejam capazes de receber informações sobre temas relacionados à ciência, à tecnologia e aos modos como estes empreendimentos se relacionam com a sociedade e com o meio ambiente e, frente a tais conhecimentos, sejam capazes de discutir tais informações, refletirem sobre os impactos que tais fatos podem representar e levar à sociedade e ao meio ambiente e, como resultado de tudo isso, posicionarem-se criticamente frente ao tema (SASSERON; CARVALHO, 2008, p. 335-336).

Nesse sentido, um cidadão para fazer uso social da ciência precisa saber ler e interpretar as informações científicas. "O ensino de ciências tem-se limitado a um processo de memorização de vocábulos, sistemas classificatórios e fórmulas por meio de estratégias didáticas em que os estudantes aprendem os termos científicos, mas não são capazes de extrair o significado de sua linguagem" (SANTOS, 2007, p. 484). 
Para Milaré e Alves Filho (2010), um indivíduo alfabetizado deve ser capaz de argumentar, negociar e dialogar com outros sujeitos, de enfrentar situações diversas e concretas de maneira racional, além de saber conduzir a relação entre saber-fazer e poder-fazer.

Segundo Gil-Pérez (2011), a alfabetização científica não deve ser restrita a um paradigma utilitarista e pragmático, mas servir como instrumento para a formação da cidadania. Freire (2001) afirma que o cidadão é o indivíduo capaz de escrever a sua própria história, tomando decisões e tendo consciência das implicações éticas que elas envolvem. Ainda segundo Freire (2011), cidadão é aquele que tem consciência de seus atos e se responsabiliza pelas decisões tomadas e suas possíveis consequências.

Alfabetizar, portanto, os cidadãos, é hoje uma necessidade do mundo contemporâneo (SANTOS; SCHNETZLER, 1997). Não se trata de mostrar as maravilhas da ciência, como a mídia já o faz, mas de disponibilizar as representações que permitam ao cidadão agir, tomar decisão e compreender o que está em jogo no discurso dos especialistas (FOUREZ, 1994).

Segundo Santos e Mortimer (2002), essa tem sido a principal proposição dos currículos com ênfase em Ciência, Tecnologia e Sociedade (CTS). Pelas inúmeras contribuições da abordagem CTS para a sociedade, acredita-se que ela precisa urgentemente ser introduzida no âmbito da escola, tornando os cidadãos mais críticos e comprometidos, capazes de compreender o mundo em que vivem, refletir e agir sobre ele (DEL PINO et al., 2016).

Considerando que cidadania se refere à participação dos indivíduos na sociedade, torna-se evidente que, para o cidadão efetivar a sua participação comunitária, é necessário que ele disponha de informações. Tais informações são aquelas que estão diretamente vinculadas aos problemas sociais que afetam o cidadão, os quais exigem um posicionamento quanto ao encaminhamento de suas soluções.

Ter noções básicas sobre o conhecimento das ciências, portanto, instrumentaliza as pessoas para que elas possam saber exigir os benefícios da aplicação deste conhecimento para toda a sociedade. Dispor de rudimentos deste conhecimento ajuda o cidadão a se posicionar em relação a inúmeros problemas 
da vida moderna, como poluição, produção, distribuição e utilização de recursos energéticos, uso de matérias-primas, doenças sexualmente transmissíveis, automedicação, entre outros.

A alfabetização científica deveria ser desenvolvida desde o início do processo de escolarização, mesmo antes de a criança ler e escrever. Nessa perspectiva, o ensino de ciências pode se constituir em um potente aliado para o desenvolvimento da leitura e da escrita [...] (LORENZETTI; DELIZOICOV, 2001).

É preciso que o professor tenha um compromisso ético com os alunos, reconhecendo que cabe a ele transformar as situações sociais em temas de discussão, promover debates e diálogos, trabalhar com assuntos que despertem o interesse e desenvolvam o senso crítico da turma.

\footnotetext{
Nesse sentido, o papel do professor não está em revelar a realidade aos educandos, mas de ajudá-los a desvendar a realidade por si só. Isso seria por meio de um processo de decodificação do mundo, como determinou Freire. Dessa forma, o papel do professor não é impor valores ou dar a solução para os problemas sociocientíficos, mas de ajudar o educando a compreender diferentes valores e alternativas para selecionar por si mesmo o caminho possível a percorrer (SANTOS, 2008, p. 126).
}

Em síntese, o ensino de ciências que poderia fazer referência com a realidade, de maneira geral, vem sendo desenvolvido, muitas vezes, de forma descontextualizada, sem despertar o interesse dos alunos. Em uma perspectiva de alfabetização científica é necessário partir do contexto do aluno, transformando a realidade em um objeto de análise e reflexão.

\section{Ciência, Tecnologia e Sociedade (CTS) e Ciência, Tecnologia, Sociedade e Ambiente (CTSA)}

Segundo Santos (2007), a ênfase curricular no ensino de ciências proposta pelos educadores desse componente tem mudado em razão de contextos histórico-sociais. No final dos anos 50 propunha-se uma educação científica para 
a Educação Básica, no sentido de preparar os jovens para adquirir uma postura de cientista. Com o agravamento dos problemas ambientais começou a surgir uma preocupação por uma educação científica que levasse em conta os aspectos sociais relacionados ao modelo de desenvolvimento científico e tecnológico.

No final da década de 70, de acordo com Santos (2007), começaram a surgir propostas curriculares para a Educação Básica com ênfase nas inter-relações Ciência-Tecnologia-Sociedade (CTS). Esses currículos apresentavam o conteúdo de ciências da natureza com enfoque nas Ciências Sociais. Tais propostas tinham uma perspectiva ambientalista, apresentando uma visão crítica ao modelo de desenvolvimento, por isso alguns a identificaram como Ciência-Tecnologia-Sociedade-Ambiente (CTSA).

O objetivo central do ensino baseado em CTS é promover a educação científica e tecnológica dos cidadãos, auxiliando o aluno a construir conhecimentos, habilidades e valores necessários para tomar decisões sobre questões de ciência e tecnologia na sociedade e atuar na solução de tais questões (SANTOS, 2007).

De acordo com Penick (1998), as aulas de CTS refletem o melhor do que conhecemos sobre como os alunos aprendem. Como essas aulas são ministradas dentro dos limites do contex to cognitivo pessoal dos alunos, espera-se que estes construam seus próprios significados, identifiquem seus próprios caminhos para a aprendizagem, perseguindo seus próprios interesses.

Santos (2006) ressalta que o movimento CTS leva em consideração os aspectos sociais. Esses currículos com enfoque nas Ciências Sociais têm como objetivo a formação de cidadãos que compreendam as interações entre os seus três componentes: ciência, tecnologia e sociedade.

Para Freire, a educação relaciona-se com conhecimento crítico da realidade, com uma leitura crítica do mundo. Para uma leitura crítica do mundo, para o desvelamento da realidade, a problematização, a desmistificação dos mitos construídos, historicamente, sobre as interações entre CTS, são fundamentais. A postura fatalista, a percepção ingênua da realidade está vinculada a esses mitos que, entre outras características, são paralisantes (AULER; DELIZOICOV, 2001). 
Segundo Roberts (1991), currículos de ciências com ênfase em CTS são aqueles que tratam das inter-relações entre explicação científica, planejamento tecnológico e solução de problemas e tomadas de decisão sobre temas práticos de importância social. A proposta de CTSA pode ser vista como uma integração entre educação científica, tecnológica e social, em que os conteúdos científicos e tecnológicos são estudados juntamente com a discussão de seus aspectos históricos, éticos, políticos, ambientais e socioeconômicos.

Santos e Mortimer (2002) destacam entre os objetivos do ensino de ciências na perspectiva CTS o desenvolvimento de valores que estão vinculados aos interesses coletivos, como os de solidariedade, de fraternidade, de consciência do compromisso social, de reciprocidade, de respeito ao próximo e de generosidade. Tais valores estão relacionados às necessidades humanas, o que significa um questionamento à ordem capitalista, no qual os valores econômicos impõem-se aos demais.

A educação CTSA poder-se-ia adotar como ponto de partida que os saberes da ciência e da tecnologia seriam referências dos saberes escolares e a sociedade e o ambiente assumiriam o papel de cenário de aprendizagem, a partir do qual surgiriam problemas e temas a serem investigados e no qual seriam aplicados os conhecimentos científicos e tecnológicos aprendidos, a fim de buscar uma solução, uma tomada de decisão [...]. A contextualização se constrói em uma etapa posterior a um processo de problematização da realidade vivida pelos alunos e da elaboração de modelos e teorias apoiados nos saberes científicos e tecnológicos. Esses saberes devem ser considerados nas tomadas de decisões e elaboração de hipóteses referentes aos problemas em estudo, esses saberes são importantes para a análise e crítica (RICARDO, 2007, p. 7).

Ainda segundo Ricardo (2007, p. 7), “a educação CTSA não esvazia a escola dos saberes teóricos, conceitos e modelos, nem os dilui em generalidades, ao contrário, exigir-se-á maior profundidade dos temas escolhidos para estudo”. Os estudos CTS configuram-se basicamente nos últimos 50 anos, sendo caracterizados por inúmeras temáticas com uma preocupação comum: uma forte interdisciplinaridade ou transdisciplinaridade de suas bases epistemológicas (BAZZO, 2002). 
Faz parte dos estudos de CTS tratar de forma integrada os diversos saberes das áreas de conhecimentos acadêmicos tradicionais, que hoje são abordados de forma fragmentada e descontextualizada. É objetivo também, ao se incorporar no ensino as preocupações com CTS, refletir sobre os fenômenos sociais e as condições da existência humana sob a perspectiva da ciência e da técnica (GARCÍA; CEREZO; LÓPEZ, 1996).

"O movimento CTS procura colocar o ensino de ciências numa perspectiva diferenciada, abandonando posturas arcaicas que afastam o ensino dos problemas sociais e adotando uma abordagem que se identifica muito com a idéia de educação científica" (TEIXEIRA, 2003, p. 182).

Por fim, é importante ter presente que a proposição da organização do currículo escolar na vertente teórica de CTS parte da compreensão da necessidade da integração das diversas áreas de conhecimento (DEL PINO et al., 2016). Nessa perspectiva, a próxima seção apresenta a proposta de levar economia para a Educação Básica com o objetivo de contribuir para a alfabetização científica de acordo com a abordagem CTS.

\section{Economia na Educação Básica}

Denegri (1998) salienta que a sociedade avança rapidamente numa realidade mundial impregnada de mudanças, cujas consequências e causas são, entre outras, de origem socioeconômica, tanto no âmbito governamental como familiar. Existe uma certa indiferença em introduzir conceitos econômicos no cotidiano das pessoas. Nas famílias, não é comum os pais discutirem com os filhos seus problemas econômicos e a Educação Básica apresenta de forma muito superficial o tema consumo nos temas transversais. No Ensino Superior, somente alguns cursos inserem os conceitos econômicos no currículo, não existe uma proposta curricular para a inclusão de tais conceitos.

O objetivo mais frequente apontado por diversos pesquisadores para os cursos com preocupação central na formação da cidadania refere-se ao desenvolvimento da capacidade de tomadas de decisão, as quais se relacionam à 
solução de problemas da vida real que envolve aspectos sociais, econômicos, tecnológicos, ambientais e políticos, o que significa preparar o indivíduo para participar ativamente na sociedade democrática.

Diante deste contexto e com ênfase na abordagem CTS, a educação financeira está entre os temas da atualidade sugeridos para compor a Base Nacional Comum Curricular (BNCC). Trata-se do conjunto de conhecimentos entendidos como essenciais para o fortalecimento da cidadania e voltados para ajudar a população a tomar decisões financeiras mais autônomas e conscientes (BRASIL, 2016). A Base Comum definirá os conteúdos que deverão fazer parte dos currículos das escolas de Educação Básica nos próximos anos, por determinação do Plano Nacional de Educação (PNE).

No Brasil, percebe-se que a educação financeira vem conquistando espaço como política a partir da publicação do Decreto ${ }^{\circ} 7.397$, de 22 de dezembro de 2010, que instituiu a Estratégia Nacional de Educação Financeira (Enef). Desde então, ações sobre a temática são compartilhadas, de forma integrada, por órgãos e entidades públicas e da sociedade, nos âmbitos federal, estadual e municipal (PRESIDÊNCIA..., 2010).

Segundo Morin (2000), embora tenha havido no século 20 grandes progressos nos conhecimentos, a excessiva especialização resultou na fragmentação dos contextos, das globalidades e das complexidades. Os problemas fundamentais e os conflitos globais estão ausentes das ciências disciplinares [...]. Nestas condições, as mentes formadas pelas disciplinas perdem suas aptidões naturais para contextualizar, ocasionando um individualismo exacerbado e centrado no domínio de saberes muito especializados, desvinculados ou distantes de questões a serem enfrentadas na realidade cotidiana, justificando-se, assim, a necessidade de um conhecimento como o da educação financeira.

Vital (2014) aponta como justificativas o envolvimento dos jovens cada vez mais cedo e frequente em decisões financeiras, nas quais é preciso saber lidar com o dinheiro, o aumento do número de produtos financeiros nos bancos tornando cada vez mais complexas as decisões na hora de escolher o melhor in- 
vestimento, as tecnologias para acesso e comercialização de produtos financeiros, o aumento da expectativa de vida, as mudanças nos sistemas previdenciários, a recente crise financeira.

Desse modo, o governo brasileiro, seguindo uma tendência mundial, elaborou uma política na qual um dos objetivos é fomentar a educação financeira para as escolas do Ensino Básico. A Enef é uma política pública ${ }^{5}$ lançada em 2010, com a finalidade de promover a educação financeira e previdenciária da população, além de contribuir para o fortalecimento da cidadania, a eficiência e solidez do sistema financeiro nacional e as tomadas de decisão conscientes por parte dos consumidores.

O ensino no Brasil, no entanto, ainda enfrenta problemas com relação ao baixo interesse dos alunos em aprender. Na maioria das escolas o professor ministra aulas no quadro negro e é visto pelos alunos como transmissor da informação, desestimulando a criatividade e o envolvimento dos estudantes, que acabam memorizando conceitos somente para serem aprovados na disciplina.

Para a maior parte dos alunos o conhecimento adquirido em sala de aula está totalmente alheio às suas experiências cotidianas, pois não existe uma conexão entre o que se aprende na escola e o mundo ao seu redor. O professor fala, o aluno escuta, o professor dita, o aluno copia, o professor decide o que fazer, o aluno faz, o professor ensina e o aluno "aprende". O professor acredita que o conhecimento pode ser transmitido, dessa forma, para o aluno.

5 Não existe uma única, nem melhor, definição sobre o que seja política pública. Mead (1995) a define como um campo dentro do estudo da política que analisa o governo à luz de grandes questões públicas e Lynn (1980), como um conjunto de ações do governo que irão produzir efeitos específicos. Peters (1986) segue o mesmo veio: política pública é a soma das atividades dos governos, que agem diretamente ou através de delegação, e que influenciam a vida dos cidadãos. Dye (1984) sintetiza a definição de política pública como "o que o governo escolhe fazer ou não fazer". A definição mais conhecida continua sendo a de Laswell, ou seja, decisões e análises sobre política pública implicam responder às seguintes questões: quem ganha o quê, por quê e que diferença faz (SOUZA, 2006, p. 24). 
Afinal qual é objetivo de ensinar? O que o aluno deve aprender? Como deve aprender? Será que o conhecimento transmitido é realmente aprendido? Muitos alunos estudam diversas disciplinas sem perceber as diferentes relações existentes entre elas e as aplicações práticas em sua vida. Então, para que aprender?

Sabe-se que a Matemática é uma das ciências aplicadas em nosso cotidiano, no entanto as aulas tradicionais ministradas não satisfazem mais às demandas atuais, os baixos desempenhos evidenciados apontam para a urgência de se buscar outras formas de (re)significar as ações pedagógicas no ensino da Matemática. A Matemática possui uma estreita relação com as outras ciências, que buscam nos fundamentos matemáticos explicações práticas para suas teorias, mas as lacunas existentes no Ensino Básico nos remetem a pensar na dificuldade que os alunos têm de compreender a Matemática como uma ciência vinculada às outras áreas do saber.

Os conceitos de economia utilizados no nosso dia a dia estão vinculados aos conceitos matemáticos, que também estão ligados a outros saberes, como a Geografia e a História, por exemplo. Percebendo um caráter interdisciplinar da ciência por excelência, interlocuções com outros campos de conhecimentos são de fundamental importância.

Acredita-se que a principal hipótese é de que as pessoas têm pouco conhecimento de economia e existe uma correlação positiva entre o conhecimento de economia e indicadores de qualidade da educação. "Se a compreensão do mundo econômico requer um indivíduo que construa uma visão sistêmica do modelo econômico social em que está inserido, a não compreensão desses modelos pode agravar os problemas sociais já existentes e criar outros como o endividamento ou o superendividamento" (DENEGRI; MARTÍNEZ; ETCHEBARNE, 2007, p. 49).

É importante lembrar que o conteúdo básico dos cursos de CTS está centrado em aspectos correlacionados da Ciência, Tecnologia e Sociedade, implicando a inclusão do tratamento de temas sociais como a educação financeira, por exemplo. Nos cursos CTS, de maneira geral, a organização se dá segundo uma abordagem interdisciplinar do ensino de ciências. 
Recentemente foi sancionada a lei 12.102, em 27 de julho de 2016, que inclui educação financeira no currículo das escolas de Ensino Fundamental e Médio da rede pública municipal de Porto Alegre (RS). A lei entrou em vigor em 2017 e preconiza que as atividades e os conteúdos relativos à educação financeira constituirão matéria da base diversificada do currículo escolar, devendo ser contemplados como tema transversal, bem como fazer parte das diferentes disciplinas do contexto escolar e serem desenvolvidos de forma interdisciplinar.

Poderão ser abordados os seguintes temas relativos à educação financeira: noções de economia monetária, fiscal e de capitais; noções de planejamento financeiro e princípios contábeis, especialmente débito e crédito. $\mathrm{O}$ artigo $\mathbf{2}^{\mathbf{0}}$ da lei 12.102 estabelece que o Conselho Municipal de Educação e a Secretaria Municipal de Educação (Smed) disponibilizarão, nas Conferências Municipais de Educação, espaço para debate, análise e articulação das atividades e dos conteúdos relativos à educação financeira, a fim de inseri-los no documento-referência que será debatido na Conferência Nacional de Educação (ZERO HORA, 2016).

O foco será ensinar as crianças a planejar gastos, lidar com o salário. Principalmente, não gastar mais do que ganha, começar pelas noções de endividamento e mostrar o que ocorre quando se gasta mais do que se ganha [...]. São noções básicas para a vida financeira adulta e que fazem a diferença. Atualmente a inadimplência é mais alta exatamente entre os jovens, que mostram não saber lidar com o dinheiro. As coordenações pedagógicas, diretores e professores serão chamados para discutir, juntos, a aplicação do conteúdo. Inicialmente, serão textos orientados. Haverá formação para professores e, em um ano, espera-se que as disciplinas já estejam abordando educação financeira como hoje fazem com direitos humanos (RBS TV, 2016).

A educação financeira tem sido um tema bastante discutido em nível nacional e principalmente internacional. Organismos representantes de diferentes países, autoridades governamentais, têm manifestado interesse crescente acerca da necessidade dos cidadãos de adquirir conhecimentos que os ajudem na condução das suas finanças pessoais, além de auxiliá-los a orçar e gerir sua renda, bem como a poupar e investir (TEIXEIRA, 2015, p. 49). 
Cabe destacar que a proposta deste artigo de contribuir na alfabetização científica não é apenas levar questões de finanças pessoais para a sala de aula, como o Banco Central vem fazendo no Ensino Fundamental do Brasil e de outros países, como a Enef e a lei $n^{\circ} 12.102$, que entrou em vigor em 2017; a ideia é levar conceitos de economia em geral para os alunos. A falta de entendimento sobre economia pode tornar-se um empecilho para a promoção do aumento do nível de bem-estar, pois uma sociedade informada é capaz de realizar as melhores escolhas.

Diante deste contexto, é importante que a alfabetização científica seja considerada um conjunto de conhecimentos que facilitam as pessoas a fazerem uma leitura do mundo em que vivem. A introdução da economia na Educação Básica, sem dúvida, tem muito a agregar ao processo de ensino e de aprendizagem das escolas, contribuindo não apenas para a $\mathrm{AC}$, por meio do caráter interdisciplinar da ciência, mas também formando pessoas mais bem orientadas a respeito da realidade socioeconômica, o que pode refletir tanto nos índices de desempenho da educação quanto no desenvolvimento econômico global do país.

\section{Conclusão}

A partir da discussão realizada no artigo percebe-se que as justificativas para defender as contribuições da economia para a alfabetização científica no ensino de ciências são diversas. Ensinar é muito mais do que transmissão de informação, é necessário fornecer possibilidades para que os conhecimentos adquiridos na escola tenham um sentido maior para os alunos.

É inaceitável ensinar ciências de maneira exclusivamente teórica, que as mostre sem vínculo com a possibilidade de realizações na vida cotidiana. Nesse sentido, percebe-se que a relação entre a alfabetização científica e a realidade vivida é a finalidade mais importante do ensino de ciências (FOUREZ, 1994). 
Faz parte dos estudos de CTS tratar de forma integrada diversos saberes que hoje são abordados de forma fragmentada e descontextualizada. De acordo com a abordagem CTS, é preciso preparar o indivíduo para participar ativamente da sociedade, saber tomar decisões e solucionar problemas que envolvam aspectos sociais, econômicos, políticos, entre outros.

O objetivo deste estudo, em uma perspectiva de alfabetização científica, possibilitou a compreensão da importância de se estabelecer relações entre economia, ciência, tecnologia, sociedade e ambiente, transformando a realidade em objeto de análise, reflexão, discussão e questionamento, possibilitando que o aluno apresente as suas ideias sobre o assunto, tornando a sala de aula um ambiente atrativo e de construção de uma ciência mais clara.

Cabe também destacar que a introdução da economia na Educação Básica pode contribuir para a alfabetização científica. Embora as políticas públicas de educação financeira forneçam valiosas contribuições na área de finanças pessoais é necessário não apenas levar educação financeira para as escolas, mas também conceitos de economia, fazer com que os alunos entendam o mundo em que vivem.

A escola deve problematizar por que o governo aumenta a taxa de juros quando tem inflação no país, por que é preciso reduzir o consumo em períodos de recessão, como uma crise internacional pode repercutir no Brasil, como uma desvalorização cambial influencia nos preços internos, como uma crise financeira, política pode repercutir no restante do mundo.

Nesse contexto, a economia está presente em nossas vidas, faz parte do nosso cotidiano. A globalização determinou uma inversão no fluxo do conhecimento. Se antigamente o sentido era da escola para a comunidade, atualmente é o mundo exterior que invade a escola com suas demandas, o conhecimento deixou de ser dado, passando a ser construído de forma interdisciplinar.

Por fim, o cotidiano, a realidade socioeconômica e a integração das diversas áreas de conhecimento devem fazer a ponte entre o que se aprende na escola e o que se vive, somente desse modo e com entusiasmo nos fazeres a aprendizagem será significativa. 


\section{Referências}

AULER, D.; DELIZOICOV, D. Alfabetização científico-tecnológica para quê? Revista Ensaio - Pesquisa em Educação em Ciências, Belo Horizonte, v. 3, n. 1, 2001.

BAZZO, W. A. A pertinência de abordagens CTS na educação tecnológica. Revista Iberoamericana de Educación, Madrid, Espanha, n. 8, 2002.

BRASIL, Ministério da Educação. Estudantes aprenderão teoria e prática de finanças nas escolas. Brasília, 2016. Disponível em: <http://portal.mec.gov.br>. Acesso em: 20 jan. 2017.

CAPRA, F. A teia da vida: uma nova compreensão científica dos seres vivos. São Paulo: Ed. Cultrix, 1996.

CHALMERS, A. A fabricação da ciência. São Paulo: Ed. da Unesp, 1994.

CHASSOT, A. A ciência através dos tempos. São Paulo: Ed. Moderna, 1994.

. Alfabetização científica - questões e desafios para a Educação. Ijuí: Ed. Unijuí, 2000.

CHASSOT, A. Alfabetização científica: uma possibilidade para a inclusão social. Revista Brasileira de Educação, Rio de Janeiro, 2003.

DEL PINO, J. C. et al. Contribuições da língua portuguesa para uma proposta de letramento científico e tecnológico no contexto escolar. Revista Eletrônica Debates em Educação Científica e Tecnológica, Vitória, n. 2, v. 6, p. 58-69, 2016.

DENEGRI, M. C. La construcción de nociones económicas en la infancia y adolescência. In: FERRO J.; AMAR, J. (Ed.). Desarrollo Humano, Perspectiva Siglo XXI. Colombia: Ediciones Uninorte, 1998.

DENEGRI, M. C.; MARTÍNEZ, G. T.; ETCHEBARNE, S. L. La comprensión del funcionamiento bancário en adolescentes chilenos: un estudio de psicología econômica. Revista interdisciplinaria, Colombia, v. 24, n. 2, p. 137-159, 2007.

DÍAZ, J. A. A.; ALONSO, A. V.; MAS, M. A. M. Papel de la educación CTS en una Alfabetización Científica y Tecnológica para todas las personas. Revista Electrónica de Enseñanza de las Ciencias, Espanha, v. 2, n. 2, 2003.

FOUREZ, G. Alphabétisation Scientifique et Technique - Essai sur les finalités de l'enseignement des sciences. Bruxelles: De Boeck-Université, 1994.

FREIRE, P. A importância do ato de ler - em três artigos que se completam. São Paulo: Cortez, 2005.

. Educação como prática da liberdade. São Paulo: Paz e Terra, 1980.

. Pedagogia dos sonhos possíveis. São Paulo: Unesp, 2001.

. Pedagogia da autonomia: saberes necessários à prática educativa. São Paulo:

Paz e Terra, 2011. 
FURIÓ, C. et al. Finalidades de la enseñanza de las ciencias en la secundaria obligatoria. Alfabetización científica o propedéutica? Revista Enseñanza de las Ciencias, Espanha, v. 19 , n. 3, p. 365-376, 2001.

GARCÍA, M. I. G.; CEREZO, J. A. L.; LÓPEZ, J. L. L. Ciencia, Tecnología y Sociedad. Una introducción al estudio social de la ciencia y la tecnología. Madrid: Tecnos, 1996. GIL-PÉREZ, D.; VILCHES-PEÑA, A. Una Alfabetización Científica para el Siglo XXI: Obstáculos y Propuestas de Actuación. Revista Investigación en la Escuela, Espanha, v. 43, n. 1, p. 27-37, 2001.

GIL-PÉREZ, D. A importância da educação científica na sociedade. São Paulo: Ed. Cortez, 2011.

HURD, P. D. Scientific Literacy: New Minds for a Changing World, Revista Science Education, Califórnia, v. 82, n. 3, 407-416, 1998.

JAPIASSU, H. Interdisciplinaridade e a patologia do saber. Rio de Janeiro: Imago, 1976. LAUGKSCH, R. C. Scientific Literacy: A Conceptual Overview. Revista Science Education, Califórnia, v. 84, n. 1, p. 71-94, 2000.

LEVY, P. Cibercultura. São Paulo: Editora 34, 1999.

LORENZETTI, L.; DELIZOICOV, D. Alfabetização científica no contexto das séries iniciais. Revista Ensaio - Pesquisa em Educação em Ciências, Brasília, v. 3, n. 1, p. 1-17, 2001.

MILARÉ, T.; ALVES FILHO, J. P. Ciências no nono ano do ensino fundamental: da disciplinaridade à alfabetização científica e tecnológica. Revista Ensaio, Rio de Janeiro, v. 12, n. 2, 2010.

MORIN, E. Os sete saberes necessários à educação do futuro. São Paulo: Cortez, 2000.

PELLA, M. O.; O'HEARN, G. T.; CALVIN, W. G. Referents to scientific literacy. Journal of Research in Science Teaching, v. 4, p. 199-208, 1966.

PENICK, J. E. Ensinando "alfabetização científica". Educar em Revista, Curitiba, n. 14, p. 91-113, 1998.

PRESIDÊNCIA DA REPÚBLICA. Decreto 7.397, de 22 de dezembro de 2010. Brasília, 2010. Disponível em: <http://www.planalto.gov.br/ccivil_03/_Ato2007-2010/2010/ Decreto/D7397.htm>. Acesso em: 16 fev. 2017.

RBS TV. Rede Brasil Sul de Televisão. Porto Alegre, 2016. Disponível em: <http:// wp.clicrbs.com.br/acertodecontas/2016/08/01/publicada-lei-que-inclui-educacao-financeira-nas-escolas-de-porto-alegre-a-partir-de-2017/?topo $=52,1,1,171, \mathrm{e} 171>$. Acesso em: 16 fev. 2017.

RICARDO, E. C. Educação CTSA: obstáculos e possibilidades para sua implementação no contexto escolar. Revista Ciência e Ensino, São Paulo, v. 1, número especial, 2007. 
ROBERTS, D. A. What counts as science education? In: FENSHAM, P. J. (Ed.). Development and dilemmas in science education. Barcombe: The Falmer Press, 1991. p. 27-55. SANTOS, W.; SCHNETZLER, R. Educação em química: compromisso com a cidadania. Ijuí: Ed. Unijuí, 1997.

SANTOS, W. L. P.; MORTIMER, E. F. Uma análise de pressupostos teóricos da abordagem C-T-S (Ciência - Tecnologia - Sociedade) no contexto da educação brasileira. Revista Pesquisa em Educação em Ciências, Belo Horizonte, v. 2, n. 2, 2002.

SANTOS, W. L. P. Letramento em química, educação planetária e inclusão social. Revista Química Nova, São Paulo, v. 29, n. 3, p. 611-620, 2006.

SANTOS, W. L. P. dos. Educação científica na perspectiva de letramento como prática social: funções, princípios e desafios. Revista Brasileira de Educação, Rio de Janeiro, v. 12, n. 36 set./dez. 2007.

SANTOS, W. L. P. dos. Educação científica humanística em uma perspectiva freireana: resgatando a função do ensino de CTS. Alexandria: Revista de Educação em Ciência e Tecnologia, Florianópolis, n. 1, v. 1, p. 109-131, 2008.

SASSERON, L. H.; CARVALHO, A. M. P. de. Almejando a alfabetização científica no ensino fundamental: a proposição e a procura de indicadores do processo. Revista Investigações em Ensino de Ciências, Porto Alegre, v. 13, n. 3, p. 333-352, 2008.

SASSERON, L. H.; CARVALHO, A. M. P. de. Alfabetização científica e tecnológica: uma revisão bibliográfica. Revista Investigações em Ensino de Ciências, Porto Alegre, v. 16, n. 1, p. 59-77, 2011.

SOUZA, C. Políticas públicas: uma revisão da literatura. Sociologias, Porto Alegre, p. 20-45, 2006. Disponível em: <http://www.scielo.br/pdf/soc/n16/a03n16>. Acesso em: 16 fev. 2017.

TEIXEIRA, P. M. M. A educação científica sob a perspectiva da Pedagogia histórico-crítica e do Movimento CTS no ensino de ciências. Revista Ciência \& Educação, São Paulo, v. 9, n. 2, p. 177-190, 2003.

TEIXEIRA, J. Um estudo diagnóstico sobre a percepção da relação entre educação financeira e matemática financeira. 2015. Tese (Doutorado em Educação Matemática) - PUC/SP, São Paulo, 2015.

VITAL, M. C. Educação financeira e educação matemática: inflação de preços. 2014. Dissertação (Mestrado) - UFJF, Juiz de Fora, Minas Gerais, 2014.

ZERO HORA. Lei 12.102, de 27 de julho de 2016. Porto Alegre, 2016. Disponível em: $<$ http://zh.clicrbs.com.br/rs/vida-e-estilo/educacao/noticia/2016/08/educacao-financeira-sera-incluida-nas-escolas-de-porto-alegre-a-partir-de-2017-7065790.html>. Acesso em: 20 jan. 2017. 